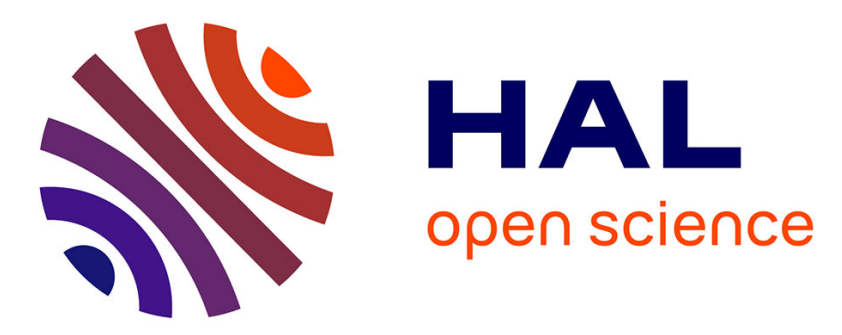

\title{
Direct copying of inflectional paradigms: Evidence from Lamunkhin Even
}

\author{
Brigitte Pakendorf
}

\section{To cite this version:}

Brigitte Pakendorf. Direct copying of inflectional paradigms: Evidence from Lamunkhin Even. Language, 2019, 95 (3), pp.e364-e380. hal-02292374

\section{HAL Id: hal-02292374 \\ https://hal.univ-lyon2.fr/hal-02292374}

Submitted on 5 Oct 2020

HAL is a multi-disciplinary open access archive for the deposit and dissemination of scientific research documents, whether they are published or not. The documents may come from teaching and research institutions in France or abroad, or from public or private research centers.
L'archive ouverte pluridisciplinaire HAL, est destinée au dépôt et à la diffusion de documents scientifiques de niveau recherche, publiés ou non, émanant des établissements d'enseignement et de recherche français ou étrangers, des laboratoires publics ou privés. 


\section{PROJECT MUSE}

Direct copying of inflectional paradigms: Evidence from

Lamunkhin Even

Brigitte Pakendorf

Language, Volume 95, Number 3, September 2019, pp. e364-e380 (Article)

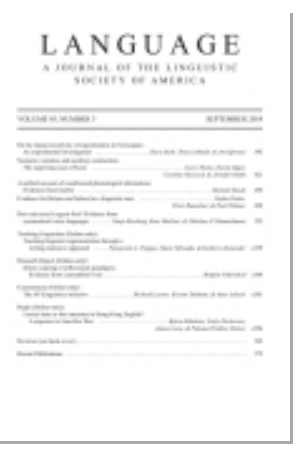

Published by Linguistic Society of America

$\Rightarrow$ For additional information about this article https://muse.jhu.edu/article/733289 


\title{
RESEARCH REPORT
}

\section{Direct copying of inflectional paradigms: Evidence from Lamunkhin Even}

\author{
BRIGITTE PAKENDORF \\ UMR5596, CNRS \& Université de Lyon
}

\begin{abstract}
Language-contact studies have shown that the transfer of morphology from one language to another is relatively rare (Gardani 2008, Grant 2012, Matras 2015), and the copying of verbal inflectional morphology is particularly infrequent (Seifart 2017). Copied morphemes are frequently assumed to enter the recipient language via 'indirect affix borrowing', whereby complex lexemes are copied and subsequently analyzed into their component parts in the recipient language, thus enabling use of the copied affixes with native roots (Grant 2012, Seifart 2015, Evans 2016). Although 'direct affix borrowing', in which speakers of the recipient language identify the meaning of affixes in the model language and transfer them directly for use with native roots, is known to occur, it has until now been identified only for derivational morphemes (Seifart 2015). I here provide evidence that inflectional morphemes, namely four Sakha (Yakut) tense-aspect-mood markers plus associated subject agreement paradigms, were copied directly into the Lamunkhin dialect of Even by fully bilingual speakers. This argument is based on the absence of Sakha verbal roots found with these paradigms in a corpus of Lamunkhin Even recordings, as well as on patterns of cooccurrence of these morphemes in clauses with Even grammatical morphology.*
\end{abstract}

Keywords: language contact, borrowing, morphology, Tungusic, bilingual utterances

1. IntRoduction. Copying of bound morphology is known to be crosslinguistically rare (e.g. Matras 2007:61, Gardani 2008, Grant 2012:104, Matras 2015:48), although intensified efforts at detecting copied morphology show that this type of contactinduced change occurs more frequently than previously assumed (Gardani 2012, Seifart 2017). There are notable differences, however, in the degree of copyability of different types of morphemes. Thus, derivational affixes are copied more frequently than inflectional morphemes, and within the latter category, markers of inherent inflection, especially plurals, are copied more frequently than contextual inflection such as structural case markers or verbal person agreement affixes (Gardani 2012, Gardani, Arkadiev, \& Amiridze 2015a:9, Seifart 2017:397). Similarly, the copying of verbal inflection is substantially less frequent than the copying of nominal inflection (Seifart 2017:424). And even though more examples of copied morphology have emerged in recent years, the copying of entire paradigms of verbal subject agreement suffixes from one language to another remains extremely rare (cf. Grant 2008:179, Gardani et al. 2015a:13), albeit not unattested. One such attested case is the Lamunkhin dialect of Even, which has copied entire paradigms of subject agreement markers together with mood suffixes from the neighboring language Sakha (Yakut), as in 1a,b. Throughout the article, ele-

\footnotetext{
* The data on which this report is based were collected during four field trips that were funded by the Max Planck Society via the MPRG on Comparative Population Linguistics and the Volkswagen Foundation via a DoBeS (Documentation of Endangered Languages) grant; this financial support is gratefully acknowledged. I am also grateful to the LABEX ASLAN (ANR-10-LABX-0081) of Université de Lyon for its financial support within the program 'Investissements d'Avenir' (ANR-11-IDEX-0007) of the French government operated by the National Research Agency (ANR). A preliminary and very different version of this paper was presented at a seminar in the 'Dynamique du Langage' research unit in Lyon in November 2016, and an amended version was presented during the colloquium 'From language mixing to fused lexts' at the Freiburg Institute for Advanced Studies in January 2017. I thank the audiences of both events for their feedback, and most especially Michael Daniel for his extensive and insightful comments following the Lyon seminar. Last but not least, I thank all of the speakers who contributed to the corpus, Natalia Aralova for access to the narratives that she recorded and glossed, Ekaterina Shadrina and Ija Krivoshapkina for transcriptions, and Ija Krivoshapkina for translations into Russian and discussions of questions.
}

$$
\text { e364 }
$$


ments of Sakha origin are underlined in examples, and morphemes of interest are in bold font; epenthetic vowels are not glossed separately, but are generally attached to the preceding morpheme. ${ }^{1}$

(1) a. Lamunkhin Even

$$
\begin{aligned}
& \text { ta-li } \quad \text { čui-li=da nanti-hn-idzi=da } \\
& \text { DIST-PROL disappear-IMP.2sG=PTL grab-LIM-ANT.CV } \\
& \text { ebehjeke:ki tute-l-li } \\
& \text { PROX.ALL.DIRECTLY run-INCH-IMP.2sG } \\
& \text { go:-j-deg-e=di: } \\
& \text { say-CONN-ASS.Y-POSS.3SG.Y=EMPH.Y }
\end{aligned}
$$

(AVZ_indjuk_internat_022) $)^{2}$

DIST-PROL disappear-IMP.2SG=PTL grab-LIM-ANT.CVB $=\mathrm{PTL}$

" "Slip through that, grab (a chicken), and run straight here," he said, right.'

b. Lamunkhin Even

$$
\begin{aligned}
& \text { hi: bolla tar dzeb-le-we-n } \quad \text { ulde-we-n } \\
& \text { 2sG DP.Y DIST eat-NR-ACC-POSS.3sG meat-ACC-POSS.3sG HESIT-SIM.CVB } \\
& \text { nọyan dzebe-d-di-mdes d d eb-uke-j-egin } \\
& \text { 3sg eat-PROG-IPFV.PTCP-SML eat-CAUS-CONN-PRS.2SG.Y } \\
& \text { 'You, however, give (people) that food of his, that meat of his to eat, as } \\
& \text { if he were eating.' }
\end{aligned}
$$

Apart from Lamunkhin Even, only two other cases of copied verbal paradigms are known: (i) the Učur dialect of Evenki, which, like Lamunkhin Even, has copied a mood suffix plus associated subject agreement markers from Sakha (Myreeva 1964:51), and (ii) the probably best-known example, Copper Island Aleut (also known as Mednyj Aleut). In this mixed language, the entire verbal inflectional morphology comes from Russian, while the nominal inflection and the majority of lexical roots are of Aleut origin (Menovščikov 1968:405, Golovko 1996, Thomason 1997). Both Učur Evenki and Copper Island Aleut are by now probably extinct, precluding further research into the factors that led to the adoption of verbal paradigms into these lects. Elucidating the process that resulted in the transfer of paradigms in Lamunkhin Even will thus further our understanding of this rare outcome of bilingual language use.

It should be noted that different authors include different phenomena in their discussions of copied (or 'borrowed') morphology. For instance, Mithun (2012) and Thomason (2015) subsume the replication of morphological patterns without actual transfer of forms under this term, and several authors include instances of copied morphemes occurring only with copied lexical items in their discussions of copied morphology (e.g. Comrie 2008, Grant 2012, Matras 2015, Evans 2016). Similarly, Adamou (2012:15256) uses the term 'paradigm transfer' to refer to the use of Turkish tense-aspect-mood

\footnotetext{
${ }^{1}$ Abbreviations used in glosses: ACC: accusative, ADJR: adjectivizer, ADVR: adverbializer, AGNR: agent nominalizer, ALL: allative, ALN: alienable, ANT: anterior, Ass: assertive, ASSOC: associative, AUG: augmentative, AUX: auxiliary, CAUS: causative, COM: comitative, CONAT: conative, COND: conditional, CONN: connective, CVB: converb, DAT: dative, DIM: diminutive, DIST: distal, DISTR: distributive, DP: discourse particle, EMPH: emphatic, F: feminine, FUT: future, GEN: genitive, HAB: habitual, HESIT: hesitative, HYP: hypothetical, IMP: imperative, INCH: inchoative, INDEF: indefinite, INS: instrumental, IPFV: imperfective, LIM: limitative, LOC: locative, M: masculine, NEC: necessitive, NEG: negative, NFUT: nonfuture, NR: nominalizer, OBL: oblique, PFV: perfective, PL: plural, POSS: possessive, PRED: predicative, PRES: presumptive, PRFL: reflexive possessive, PROG: progressive, PROL: prolative, PROX: proximal, PRS: present, PST: past, PTCP: participle, PTL: particle, Q: question, QUAL: qualitative, R: Russian copy, RES: resultative, SG: singular, SIM: simultaneous, SML: similative, TRM: terminative, VAL: valency change, Y: Sakha (Yakut) copy.

${ }^{2}$ Unless otherwise indicated, examples are taken from the corpus of oral recordings on which this article is based; see n. 3 .
} 
(TAM) plus subject agreement markers on verbs of Turkish origin in Romani, a phenomenon for which Matras (2015:66-75) uses the term 'morphological compartmentalization'. This outcome of language contact was extensively described and discussed by Kossmann (2010) under the label of 'parallel systems borrowing'. Others, most notably Gardani (2012:72) and Seifart (2012:473), restrict their definition of copied morphology to those cases where copied morphemes are used with at least a few inherited lexemes, a terminology that I follow as well (cf. Pakendorf 2015:163-64). Thus, the phenomenon discussed in this report concerns the transfer not of structural patterns, but of actual forms. Furthermore, as can be seen in example 1 and as is shown in detail in $\S 4$ below, the verbal paradigms copied from Sakha into Lamunkhin Even are not restricted to copied Sakha verbs, but are used predominantly with native Even verb stems.

Seifart (2017:409) has suggested that copied verbal paradigms are first introduced via wholesale copying of inflected stems, which later get reanalyzed into their component roots and morphemes by speakers of the recipient language, allowing use of the subject agreement paradigms with inherited verb stems. The suggestion that verbal inflectional paradigms are copied indirectly via complex lexemes is in accordance with data from bilingual interactions, since it is widely assumed that '[i]n a multilingual communication setting, the choice of "language" amounts to the choice of structures used to anchor the predication and its arguments (verb-inflectional morphology such as person, tense, modality and aspect)' (Matras 2015:48). Similar observations have led Myers-Scotton (e.g. 2008:22-23; see also Jake \& Myers-Scotton 2009:214) to suggest that in situations of code-switching the matrix language of bilingual utterances, which provides the grammatical frame for the mixed clause, is determined by so-called 'outsider morphemes', which include subject agreement markers. Structural morphology from the embedded language is generally found only in so-called 'embedded language islands', complete phrasal constituents consisting only of embedded language material (Myers-Scotton 2002:139, Jake \& Myers-Scotton 2009:210).

In contrast to the assumption that subject agreement paradigms are copied via the transfer of foreign verb stems plus inflection markers, with segmentation of the morphemes for use with native stems occurring only at a later stage, I here argue that the copied paradigms in Lamunkhin Even are the result of what Seifart (2015) calls 'direct affix borrowing'. This implies that fully bilingual speakers can segment lexemes into their component parts in both of their languages and freely insert subject agreement suffixes from one language into the other.

The paper is structured as follows: I first describe the copied paradigms in Lamunkhin Even $(\S 2)$, and then briefly introduce the distinction between indirect and direct affix copying $(\S 3)$. In $\S 4$ I present the data in favor of my argument that the paradigms of Sakha origin found in Lamunkhin Even were copied directly. An alternative hypothesis is discussed in $\S 5$, namely, that the clauses containing Sakha verbal morphology actually have Sakha as their matrix language, while the Even elements are merely embedded. The report ends with a discussion and conclusions (§6).

2. Copied PARAdigms IN LAMUNKhin EVEN. ${ }^{3}$ Lamunkhin Even is the westernmost still-viable dialect of Even, a North Tungusic language with a scattered distribution over

\footnotetext{
${ }^{3}$ This article is based on a corpus of approximately eleven hours of transcribed, translated, and glossed oral recordings (amounting to nearly 52,000 Even words) collected in four field trips to Sebjan-Küöl between 2008 and 2012. The corpus comprises mainly monologues, especially autobiographical narratives and anecdotes, but it also includes an hour-long conversation among four speakers. Thirty-six speakers aged eleven to seventy-eight years at the time of recording are represented, twenty-four females and twelve males.
} 
much of northeastern Siberia. Like other Even dialects Lamunkhin Even is morphologically rich, exclusively suffixing, and fairly agglutinative. It is spoken in the village Sebjan-Küöl in central Yakutia by approximately 300-350 individuals (out of some 850-900 inhabitants in total). While there are still some children who are acquiring Even as their home language in Sebjan-Küöl, the lect is under severe pressure from the Turkic language Sakha, and practically everyone who speaks Lamunkhin Even knows Sakha as well. This pressure has led to noticeable Sakha influence in Lamunkhin Even (see e.g. Pakendorf 2009:89-90), including the influx of large numbers of Sakha lexemes.

The most noticeable and notable impact of the intense pressure exerted by Sakha is the presence of copied verbal inflectional paradigms, consisting of a Sakha mood suffix with associated Sakha subject agreement suffixes (Pakendorf 2009, 2014, 2015). For example, comparing the Lamunkhin necessitive in $2 \mathrm{a}$ with the necessitive from the eastern Ola Even dialect (which is not in contact with Sakha) in $2 \mathrm{~b}$ and the Sakha necessitive in $2 \mathrm{c}$ shows that not only has the Sakha necessitive mood marker -iexte: $\chi$ (which in $2 \mathrm{c}$ is merged with the verb root hie- 'eat') replaced the Even necessitive suffix -nne in Lamunkhin Even, but the Lamunkhin Even subject agreement marker -kin is identical to Sakha $-\chi$ in and has replaced the Even 2sG person marker $-s$.

(2) a. Lamunkhin Even

koke-če bej dzebe-d-di-mdes dzebe-jekte:k-kin

die-PFV.PTCP human eat-PROG-IPFV.PTCP-SML eat-NEC.Y-PRED.2SG.Y

'You have to eat as if the deceased is eating.'

b. Ola Even (Novikova 1980:109; glosses and English translation mine) hi: čakabak-la tore-nne-s

2SG meeting-LOC speak-NEC-2sG

'You have to speak at the meeting.'

c. Sakha

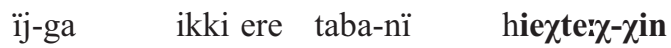

month-DAT two only reindeer-ACC eat.NEC-PRED.2SG

'Per month you must eat [i.e. are allowed to eat] only two reindeer.'

Far from all of the inherited TAM forms have been replaced in Lamunkhin Even: the imperative, subjunctive, and indicative past, nonfuture, and future are all of Even origin. Nor has the Sakha subject agreement marking replaced the inherited Even person markers for all TAM forms (in contrast to what is stated by Seifart 2017:table 13 and p. 423), as shown by 3a,b: in 3a, the past-tense suffix -ti/-ri combines with the 2 sG subject agreement suffix $-s$ (which is identical to the nominal possessive suffix and also found with the Even necessitive in $2 b$ ), whereas in $3 b$ the nonfuture tense takes the $2 \mathrm{sG}$ subject agreement suffix -nni. This is consistent with the structure of Even, where specific TAM forms take different sets of subject agreement markers.

(3) a. Lamunkhin Even iadaj tarak asatkam ya:t-ti-s eiri-ri-s hi: what.for DIST girl.ACC call-PST-2SG call-PST-2SG 2SG

'Why did you invite that girl?'

b. Lamunkhin Even ZAS_arrival_Tashkent_016) hi: keńeli o:-nni go:n-če min-u e-he-nni 2sG bad make[NFUT]-2SG Say-PFV.PTCP 1SG.OBL-ACC NEG-NFUT-2SG dọlda-r go:n-če hear-NEG.CVB say-PFV.PTCP

“"You did (something) bad, you didn't listen to me," he said.' 
The paradigms copied into Lamunkhin Even are the necessitive illustrated in 2a, the assertive illustrated in $1 \mathrm{a}$, the present indicative shown in $1 \mathrm{~b}$, and the hypothetical shown in 4 below. In each case, the Sakha mood marker was copied together with the corresponding set of Sakha subject agreement suffixes (see Tables A1-A4 in the appendix). It should be noted that in Lamunkhin Even the Sakha present indicative occurs with a future or necessitive reading as well, depending on the context.

(4) Lamunkhin Even

$$
\begin{aligned}
& \text { ta-du go:n-e-m ogi-de-du ibga-w nan=da teti-je:kkin } \\
& \text { DIST-DAT say-NFUT-1sG top-SIDE-DAT good-ACC and=PTL wear-HYP.2sG.Y } \\
& \text { [na:da] } \\
& \text { [need.R] } \\
& \text { 'to that I say [reply] "on the top you need to put on something good as } \\
& \text { well", }
\end{aligned}
$$

Given that practically every speaker of Lamunkhin Even is also fluent in Sakhawith Sakha probably being the dominant language of several individuals who contributed to the narrative corpus - identifying established copies is not an easy task. Nevertheless, an analysis of the frequency of use (Table 1) demonstrates that the assertive and the necessitive can probably be considered established copies, while the present indicative and the hypothetical are best considered ongoing copies.

\begin{tabular}{lcccc} 
& \multicolumn{2}{c}{ SAKHA COPY } & \multicolumn{2}{c}{ EVEN FORM } \\
& \# TOKENS & \# SPEAKERS & \# TOKENS & \# SPEAKERS \\
ASSERTIVE & 59 & 20 & N/A & N/A \\
NECESSITIVE & 90 & 18 & 17 & 5 \\
PRESENT TENSE & 53 & 17 & hundreds & 36 \\
HYPOTHETICAL & 19 & 10 & $\sim 50$ & $\sim 17$
\end{tabular}

TABLE 1. Comparison of frequency of use of Sakha copies vs. Even forms. ${ }^{4}$

Thus, the assertive and necessitive are widely used by many speakers, including those who are arguably dominant in Even, and the copied necessitive occurs far more frequently than the inherited Even forms ${ }^{5}$ (there is no inherited Even form that fulfills the functions of the assertive). The Sakha present indicative and the hypothetical, by contrast, are used predominantly by speakers who probably use Sakha more in their everyday interactions, and the inherited Even forms are used more frequently and by more speakers than the copied forms. Furthermore, my main consultant, for whom Lamunkhin Even is arguably the dominant language, commented negatively on the copied present tense used by some speakers, whereas she found no issue with the copied assertive or necessitive, which she herself frequently uses and considers an integral part of Lamunkhin Even. As to the copied hypothetical, while she did produce it in an elicitation task, she explicitly flagged it as the Sakha form. All of these arguments lead me to judge the assertive and necessitive as established copies in Lamunkhin Even,

\footnotetext{
${ }^{4}$ Note that there is no one-to-one correlation of the functions of the Sakha present tense and the Even nonfuture, so a precise count of the present-tense uses of the Even nonfuture is impossible; however, there are over 2,000 tokens of this tense form in the corpus. Similarly, there is no single Even form that covers the meaning of the Sakha hypothetical; the count is based on searches in the translation line of 'can', 'able', and 'cannot', as well as tokens of the the presumptive suffix - $\check{c} A$ :d $\zeta i$ without a probability reading and the Even suffix -dzinA, which in Lamunkhin Even is used in a similar vein as the copied Sakha hypothetical.

${ }^{5}$ Of the five speakers who used the Even necessitive, two are teachers of Even trained to use the 'literary' Even forms (illustrated in the Ola Even example in 2b), and one is a strong advocate of using 'literary' Even. Two of the five (including one of the teachers) also used the Sakha necessitive.
} 
while the present tense and hypothetical forms are still in the process of being copied (see also Pakendorf 2015:172).

In Sakha, the affirmative assertive can be expressed either synthetically, with the mood and person suffix attaching to the verb stem, or via an analytical construction, in which the lexical verb carries a participial suffix and the mood marker is attached to the auxiliary buol-. The Sakha negative assertive is only expressed via such an analytical construction (Pakendorf 2009:95-96). In Lamunkhin Even, all three assertive constructions are found: the synthetic affirmative (5a), the analytical affirmative making use of the Sakha present participle (5b), and the analytical negative (5c).

(5) a. Lamunkhin Even

burduka-na-tna

man-u-j-dag-a

(AXK_1930s_106)

flour.R-ALN-POSS.3PL use.up-VAL-CONN-ASS.Y-POSS.3SG.Y PTL

upe:-ńdze-je-1-bu

grandmother-AUG-ASSOC-PL-POSS.1sG

'My grandmother and them's ${ }^{6}$ flour had run out, right.'

b. Lamunkhin Even

(IVK_memories_109)

hatakka egdze-kie-meje-l ńaldańa-maja-l

in.addition.Y big-EMPH-AUG-PL coal.black-AUG-PL

ič-u-jer

bol-lak-tara

SEe-VAL-CONN-PRS.PTCP.Y AUX.Y-ASS.Y-POSS.3PL.Y

'In addition they looked huge and black.'

c. Lamunkhin Even

(AVZ_indjuk_internat_037 [ex. 13 in Pakendorf 2015])

indjuk gerbe bi bolla ha:-j-bat bol-lag-im

turkey.R name 1sG DP.Y know-CONN-NEG.Y AUX.Y-ASS.Y-POSS.1SG.Y

iak=kol tarbača-maja-w huta-ku

what=INDEF DIST.QUAL-AUG-ACC become.red-ADJR

'It's called "indjuk" [turkey], and I didn't know that, right, something like that big red (creature).'

As mentioned in the introduction, Seifart (2017:409) suggests that subject agreement paradigms such as those found in Lamunkhin Even might enter the recipient language via indirect affix copying. In the following section I briefly introduce the distinction between indirect and direct affix copying.

3. INDIRECT VS. DIRECT AFFIX COPYING. Several authors have noted that copied morphology can 'sneak into' a recipient language via the transfer of fully inflected lexemes (Weinreich 1953:31, Matras 2009:209, Meakins 2011:74, Grant 2012:118-19, Seifart 2015, Evans 2016:31), with the morphemes being segmented and transferred to inherited roots only at a later stage. This process is termed variously 'backwards diffusion' (Matras 2009:209), 'retroactive transfer' (Grant 2012:105), 'trojan horse borrowing' (Evans 2016:31, using a term coined by Meakins 2011), or 'indirect affix borrowing' (Seifart 2015). I here follow Seifart's terminology; however, since the term 'borrowing' is used in different ways by different authors (see Pakendorf 2007:26-31 for discussion, and Johanson 1992:175 for further criticism of this term), I prefer to use 'copying' instead of 'borrowing' to refer to the transfer of items from one language to another in situations of language contact. I therefore use the terms 'indirect affix copying' and 'direct affix copying'.

In indirect affix copying, speakers of the recipient language first copy large numbers of complex lexemes containing one and the same affix attached to a variety of roots; the

\footnotetext{
${ }^{6}$ Though nonstandard English, this translation is the best rendition of the Even associative plural.
} 
presence of these complex copies enables them to identify the meaning of the affix, which they subsequently segment and use productively in combination with inherited roots. The best-described example of this process is the integration of the French suffix -able into English, where it now productively derives words such as knowable or workable (Seifart 2015:511).

However, as shown by Seifart (2015), morphemes can enter a recipient language not only via such indirect affix copying but also via direct affix copying. In direct affix copying speakers of the recipient language have sufficient knowledge of the model language to permit them to identify the meaning of an affix in situ; they thus copy the affix directly into the recipient language, without first copying large numbers of complex forms.

A prerequisite for indirect affix copying to take place is the presence of complex copies consisting of a model-language root plus the model-language affix in the recipient language (Seifart 2015:513, Evans 2016:31). Seifart (ibid.) argues that it is furthermore important that the recipient language should have copied not only complex lexemes, but also the plain root without affixes, enabling speakers to identify the meaning of the transferred morphemes and thus extend their use to native roots. In contrast, if no complex copies can be found in the recipient language, 'then the affix can only be taken from knowledge of the donor language, that is, through direct borrowing' (Seifart 2015:513). In his crosslinguistic study, Seifart (2015) identifies direct affix copying only for derivational morphemes, in particular for morphemes involved in numeral derivation.

With respect to inflectional morphology, Evans (2016:31) suggests that this might enter the recipient language 'in the form of borrowed words that host the relevant paradigms, with the extension to native stems being a later process', that is, via indirect affix copying. Seifart (2017:409), too, suggests that verbal subject agreement markers may have been copied via indirect affix copying. As I argue in the following, however, the four verbal paradigms copied into Lamunkhin Even from Sakha are most likely the result of direct affix copying.

4. EVIDENCE FOR DIRECT AFFIX COPYING OF SAKHA PARADIGMS INTO LAMUNKHIN EVEN. The presence of copied inflectional paradigms in Lamunkhin Even is striking and calls for an explanation of the underlying process that led to this rare outcome. The most straightforward hypothesis is that they first entered the language via monolingual embedded language constituents in cases of code-switching (cf. Jake \& Myers-Scotton 2009:219, Meakins 2011). If these occurred with high enough frequency, and if the corresponding Sakha roots also occurred by themselves in Lamunkhin Even discourse, the meaning of the recurrent suffixes in the embedded language constituents could have been identified by the speakers of Lamunkhin Even and subsequently been used with verb stems of Even origin; that is, such code-switched constituents might have served as the basis for indirect affix copying.

If this hypothesis were true, we would expect to find the Sakha inflectional morphemes occurring together with Sakha verb stems (cf. Seifart 2015:513, Evans 2016: 31). As is evident from Table 2, however, this is not at all what we find. Instead of the Sakha verbal morphemes occurring predominantly or at least frequently with Sakha stems, the vast majority of tokens of the copied suffixes occur only with Even stems.

Of course, it is debatable whether a corpus consisting of a mere $\sim 52,000$ tokens produced by $\sim 10 \%$ of the speech community is really representative of Lamunkhin Even as a whole, all the more so as audio and video recordings in the presence of foreign linguists are highly artificial speech situations. In addition, such a corpus provides only a synchronic slice of the lect, and as such might not really permit diachronic analyses. But the corpus probably does provide a fairly representative sample of the speech com- 
NECESSITIVE

ASSERTIVE (SYNTHETIC)

ASSERTIVE (ANALYTICAL)

ASSERTIVE (NEGATIVE)

PRESENT TENSE

HYPOTHETICAL

TYPES
34
28
19
4
26
10

TOKENS
90
39
20
5
53
19

SAKHA VERB

0

2

1

2

0

0

TABLE 2. Frequency of verb stems occurring with Sakha verbal morphology in the Lamunkhin Even narrative corpus. ${ }^{7}$

munity, since a relatively broad range of speakers is included, from children and teenagers up to elderly speakers; it also encompasses individuals with diverse occupations, from reindeer herding to teaching. Furthermore, a third of the recordings were undertaken in somewhat natural settings, involving at the least a native speaker of Even as audience and interlocutor, and some speakers who faced only the recording linguist(s) got so carried away by their narrative that they clearly forgot about the microphone and camera. Thus, the corpus probably does reflect relatively naturalistic speech overall. Lastly, given that the present-tense and hypothetical-mood paradigms are likely still in the process of being copied, while the necessitive and assertive paradigms appear to be well-established copies, as argued in $\S 2$, the corpus does appear to provide a snapshot of change in progress that can be used for historical investigations. Taking all of these points together, it appears reasonable to extrapolate conclusions drawn on the basis of the corpus data to Lamunkhin Even and the copying process as a whole.

As can be seen from Table 2, none of the tokens of the Sakha necessitive, presenttense indicative, or hypothetical mood occur with Sakha verbs in the corpus; they occur exclusively with Even verbs. Only the assertive occurs with Sakha verbs, although the synthetic and analytical affirmative constructions occur far more frequently with Even verbs than with Sakha verbs. This finding is highly unexpected and clearly indicates that the paradigms are not being transferred via indirect affix copying.

It should be noted that this surprising finding is not due to an aversion on the part of Lamunkhin Even speakers to copying Sakha verbs: seventy-one verbs of Sakha origin are found in the corpus, of which fifty-nine occur only with Even morphology, eight occur only with Sakha morphology (not just the suffixes discussed in this report, but also converbal suffixes, and including clear examples of alternational code-switching, that is, switches between languages at clause boundaries or at turn-taking), and four occur with both Sakha and Even morphology. Fifteen of these Sakha verb roots are used by three or more speakers, and five more are used by two different speakers. This clearly indicates that if the Sakha mood paradigms had indeed entered Lamunkhin Even via embedded language constituents and indirect affix copying, one should expect to see complex copies consisting of Sakha verb stems with Sakha inflectional morphology, especially with the present tense and hypothetical suffixes.

Table 3 lists the Sakha verb stems that occur with the Sakha assertive in the corpus. Of these, ülele:- 'work' seems to be treated as an Even verb ${ }^{8}$ since the Sakha morphology is integrated with a connective glide (6). This connective glide, which occurs only in Lamunkhin Even, is used exclusively when Sakha verbal suffixes are connected to Even

\footnotetext{
${ }^{7}$ For the type and token counts, the Sakha TAM forms include the Sakha subject agreement markers that are associated with them.

${ }^{8}$ It should nevertheless be noted that the native Even stem gurge:wči- is vastly more frequent, with 105 tokens occurring in the corpus.
} 
verb stems (see 1a,b or 5a-c above), ${ }^{9}$ not in the integration of Sakha roots into Even morphology (Pakendorf 2009:97). Thus, of the affirmative assertive forms occurring in the corpus, arguably only two occur with Sakha verb stems (namely hïsta- 'get infected' and eppietes- 'answer'), as opposed to forty that occur with Even verb stems. ${ }^{10}$

VERB
ülele:- 'work'
hïsta- 'get infected'
eppietes- 'answer'
bil- 'know'
tik- 'sew'

$\quad$ ASSERTIVE
CONSTRUCTION
synthetic
synthetic
analytical affirmative
negative
negative

\begin{tabular}{cc}
\multicolumn{2}{c}{ \# OF TOKENS IN CORPUS WITH } \\
SAKHA MORPHEMES & EVEN MORPHEMES \\
1 & 14 \\
1 & 1 \\
1 & 0 \\
2 & 0 \\
1 & 0
\end{tabular}

TABLE 3. Sakha verbs with assertive morphology.

(6) Lamunkhin Even

(AEK_childhood_123) tar nọjan sahïl perme-du-n

DIST 3sG fox.Y farm.R-DAT-POss.3sg

$\underline{\text { ülele-j-deg-e }=\text { di: }}$

work.Y-CONN-ASS.Y-POSS.3sG.Y=EMPH.Y

'Well he worked on the fox farm, right, ...'

The two examples of the affirmative assertive with Sakha verb stems $(7 \mathrm{a}, \mathrm{b})$ involve verbs that practically do not otherwise occur in the corpus (the verb hïsta- 'get infected' was used twice by the same speaker). This contrasts with several Even verbs, such as koke- 'die', go: $n$ - 'say', or hor- 'go', that were used with affirmative assertive forms by different speakers. It is thus highly unlikely that such rare instances of Sakha verb stems found in the Lamunkhin Even affirmative assertive construction pool, where they are far outweighed by Even verb stems, would have served as the model for indirect copying of the affirmative assertive forms.

(7) a. Lamunkhin Even

(AEK_childhood_033)
bïlïgï
bej
il-la-n $=$ da
girka-hyara-n

previous. Y human stand.up-NFUT-3sG=PTL walk-LIM.HAB[NFUT]-3sG

ta-du hïsta-dag-a

DIST-DAT get.infected.Y-ASS.Y-POSS.3sG.Y

'In the past, a person would get up and walk off, and catch this (disease).'

b. Lamunkhin Even

otton mut ebe-di-t=de

(AVZ_indjuk_internat_079)

DP.Y 1PL Even-ADJR-INS=PTL speak-CONAT-COND.CVB-1PL

nóka-di-t eppietteh-er

Sakha-ADJR-INS answer.many.times.Y-PRS.PTCP.Y

\section{bol-lak-tara}

AUX.Y-ASS.Y-POSS.3PL.Y

'Even if we try to speak Even (with them), they answer in Sakha.'

The only candidate for indirect affix copying is the negative assertive: two of the four verb types found in the corpus are Sakha $(8 \mathrm{a}, \mathrm{b})$, and two are Even $(5 \mathrm{c}$, repeated here

\footnotetext{
${ }^{9}$ The exceptions are the necessitive and hypothetical, which themselves start with a glide.

${ }^{10}$ This number is the total number of verb types found with the synthetic and analytical assertive in Table 2 (forty-seven), minus five types that occur in both constructions and not counting the two types of Sakha origin.
} 
as $8 \mathrm{c}$, and $8 \mathrm{~d}$ ), with $8 \mathrm{a}$ clearly representing a Sakha clause with an embedded Even direct object.

(8) a. Lamunkhin Even unta-wu

(AEK_childhood_083 [ex.17b in Pakendorf 2009]) fur.boots-ACC.POSs.1sG DP.Y not.be.able.Y sew.Y-NEG.Y

\section{buol-lag-im $=$ di:}

AUX.Y-ASS.Y-POSS.1SG.Y=EMPH.Y

'Fur boots I cannot sew, right.'

b. Lamunkhin Even tar amarra mut bil-bet (RDA_old_remains_traditions_043)

DIST later 1PL know.Y-NEG.Y AUX.Y-ASS.Y-1PL.Y who that ga-ča:dzi-r take-PRES-3PL

'Later we don't know who took it.'

c. Lamunkhin Even (AVZ_indjuk_internat_037 [ex. 13 in Pakendorf 2015]) indjuk gerbe bi bolla ha:-j-bat bol-lag-im turkey.R name 1sG DP.Y know-CONN-NEG.Y AUX.Y-ASS.Y-POSS.1sG.Y iak $=$ kol tarbača-maja-w huta-ku what=INDEF DIST.QUAL-AUG-ACC become.red-ADJR

'It's called "indjuk" [turkey], and I didn't know that, right, something like that big red (creature).'

d. Lamunkhin Even
kiajan girka-j-bat not.be.able.Y walk-CONN-NEG.Y AUX.Y-ASS.Y-POSS.1sG.Y circle ọ:-kan begi-če, ... become-TRM.CVB freeze-PFV.PTCP
'I can't walk, right, (my legs) froze until they reached such a diame- ter ...'

(AEK_childhood_087 [ex. 10d in Pakendorf 2009])

As stated by Seifart (2015:513; emphasis mine): 'The presence of complex loanwords is a necessary condition for indirect borrowing. IF THERE ARE NONE, then the affix can only be taken from knowledge of the donor language, that is, THROUGH DIRECT BORROWING'. Since the necessitive and, more importantly, the present-tense indicative and the hypothetical-mood forms, which were argued to still be in the process of being copied into Lamunkhin Even, occur exclusively with Even verb stems, the obvious conclusion appears to be that these were/are being copied directly. In addition, as argued above, even the affirmative assertive appears more likely to be the result of direct than indirect copying. However, as is discussed in the following, there is an alternative hypothesis that needs to be investigated before this conclusion can be firmly reached.

5. DiRECT COPYING OF SAKHA VERBAL PARADIGMS OR SAKHA UTTERANCES WITH EMBEDDED EVEN ITEMS? The data discussed in $\S 4$ seem to speak for themselves: not a single token of a complex copy consisting of a Sakha root plus Sakha suffixes is found in the corpus for the necessitive, present-tense, or hypothetical paradigms. The conclusion would thus seem obvious: these paradigms - plus, as I argue above, the affirmative assertive forms - can only have been copied directly. But there is of course an alternative explanation for the findings: since subject agreement morphology is considered to define the matrix language of an utterance in bilingual language use (Myers-Scotton 2008:23, Jake \& Myers-Scotton 2009:214, 216, Matras 2015:48), perhaps all of these instances of supposedly directly copied Sakha suffixes in Lamunkhin Even actually 
represent Sakha utterances with embedded Even elements. This would hold in particular for the present-tense indicative and hypothetical forms, which I argue are still in the process of being copied (see §2). This suggestion is not at all implausible, given that practically all speakers of Lamunkhin Even, and definitely all of the speakers who contributed to the corpus, are bilingual in Sakha. ${ }^{11}$

A closer look at the data shows that there are indeed several utterances in which Sakha might arguably be the matrix language, for example, the negative assertive construction in $8 \mathrm{a}$ above, the hypothetical construction in $9 \mathrm{a}$, or the synthetic assertive and present tense in $9 \mathrm{~b}$. Note that in $9 \mathrm{a}$, the noun phrase is equally likely to be Sakha or Even, since the noun is a Russian copy and the enclitic particle $=t a$ is shared by both languages. Of these, $8 \mathrm{a}$ and $9 \mathrm{a}$ were uttered by speakers who are probably and clearly linguistically dominant in Sakha, respectively: the speaker from whose narrative 8a was taken grew up in a Sakha foster home and repeatedly said she did not know how to speak Even, while in response to a sociolinguistic questionnaire the speaker who uttered 9a claimed to speak only Sakha, both with her parents as a child and with her husband. Furthermore, the utterance in $9 \mathrm{a}$, which is taken from a conversation, is preceded by an utterance by the same speaker that is similarly likely to have Sakha as matrix language. In contrast, both $8 \mathrm{a}$ and $9 \mathrm{~b}$ are preceded and followed by Even clauses and would thus represent switches in matrix language.

(9) a. Lamunkhin Even

kredit $=$ ta ga-jaktarin höp

credit.R=PTL take-HYP.3PL.Y PTL.Y

'they could also take a credit'

b. Lamunkhin Even

bi: buollar ye:le-le-j-er buol-lag-ïm

(beseda_2020_IAS)

1sG DP.Y be.afraid-INCH-CONN-PRS.PTCP.Y AUX.Y-ASS.Y-POSS.1sG.Y

ol ihin dze dze hore-je-ebin

therefore.Y PTL.Y PTL.Y go-CONN-PRS.1sG.Y

'And I got frightened, therefore I went [i.e. married him].'

There are also several examples in the corpus, however, where the hypothesis that Sakha might be the matrix language is a lot harder to argue for, such as 4 and $5 \mathrm{c}$ above and $10 \mathrm{a}-\mathrm{c}$. In all of these examples, the Sakha TAM and subject agreement suffixes are practically the only Sakha elements, and, more importantly, grammatical case suffixes are Even. Like subject agreement markers, structural case markers belong to the 'outsider morphemes' that define the matrix language of bilingual utterances (Myers-Scotton 2008:22, Jake \& Myers-Scotton 2009:214). These examples would thus appear to have two matrix languages, both Even and Sakha-yet according to Myers-Scotton's theory, which Jake and Myers-Scotton (2009:234-35) support with numerous examples from different bilingual situations, even in 'composite code-switching' only one matrix language furnishes the outsider morphemes.

\footnotetext{
${ }^{11}$ Actually, they are probably all trilingual in Even, Sakha, and Russian - but the impact of Russian on Lamunkhin Even appears negligible. Even Russian copies appear to have entered the lect via Sakha, as shown by their phonology (in the examples they are nevertheless indexed as Russian copies).
} 
(10) a. Lamunkhin Even

ńoguhub-ba-n

ma:-ridzi bolla bej-te[n]

(RDA_TPK_death_115)

lead.reindeer-ACC-POSs.3sg kill-ANT.CVB DP.Y human-DISTR

beje-l-du bo:-če-jegin go:li beje-s

human-PL-DAT give-RES-CONN-PRS.2SG.Y PTL self.Y-POSS.2SG

dzeb-dzi-nni

eat-FUT-2sG

'Having killed the lead reindeer, however, you give (the meat) to people, right, you yourself eat.'

b. Lamunkhin Even

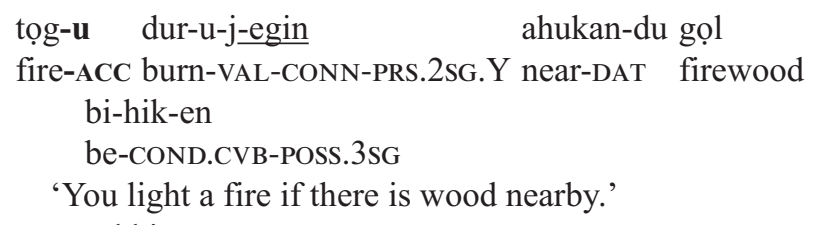

'You light a fire if there is wood nearby.'

c. Lamunkhin Even

bi gia-čal ḑe tor-re ujamkam

1sG friend-COM well.Y earth-LOC mountain.sheep.ACC
ujamkam=gu
bujum $=$ gu
bujuse-ridzi
mountain. sheep. $\mathrm{ACC}=\mathrm{Q}$ wild.reindeer. $\mathrm{ACC}=\mathrm{Q}$ hunt-ANT.CVB

mai-mi bi gia-di bo:-jekte:k-pin

kill-COND.CVB 1sG friend-DAT.PRFL.SG give-NEC.Y-PRED.1sG.Y

ere-w

PROX-ACC

'If I kill a mountain sheep or a wild reindeer while hunting with my friend, I have to give this (carcass) to my friend.'

Furthermore, there are examples where such a supposed switch in matrix language would be occurring across very tightly connected clauses, as in la above, where the matrix language of the direct speech is Even, while the main clause would have Sakha as matrix language, or in $7 \mathrm{~b}, 10 \mathrm{~b}$, and 11 , where the matrix language of the subordinate clause is Even, while the matrix language of the main clause would be Sakha. While this might in theory be possible (Jake \& Myers-Scotton 2009:209), it appears rather implausible.

(11) Lamunkhin Even bujusi-mya ńari bujun-dule hore-d-dek-en $\quad$ (stado\#10_SEN_traditions_021) hunt-AGNR man wild.reindeer-LOC go-PROG-COND.CVB-3SG woman e-jekte:k nọyman koje:t-te e-jektẹ nộandun NEG-NEC.Y 3sG.ACC look.at-NEG.CVB NEG-NEC.Y 3sG.DAT to:di-t-te ńari hiwkejken beje-n hore-jekte:k help-RES-NEG.CVB man quietly self.Y-POSS.3sG go-NEC.Y

'When a man, a hunter goes after wild reindeer, the woman mustn't look at him, mustn't help him, the man has to leave quietly by himself.'

The following interesting example (12a) provides further evidence that the matrix language in utterances with Sakha TAM and subject agreement suffixes is Even, not Sakha. This clause contains the verb root $i a$ - 'do what', which in Lamunkhin Even functions as a placeholder for verbs when the correct lexical root is not immediately accessible. As shown by $12 \mathrm{~b}, \mathrm{c}$, this hesitative marker is fully specified for the TAM and subject agreement to be carried by the lexical verb. In 12a, however, the hesitative car- 
ries Even TAM and subject agreement marking, while the lexical verb carries the Sakha present tense and associated Sakha subject agreement suffix. As noted above, in Lamunkhin Even the Sakha present tense carries not only present-tense meaning, but depending on the context it can have future meaning as well, explaining this apparent shift in tense between the hesitative and the lexical verb. Given the fact that the hesitative marker carries Even subject agreement morphology and thus defines the matrix language of the clause as Even, it is hard to argue that the Sakha subject agreement morphology on the lexical verb represents Sakha as the matrix language. Rather, this example shows that the Sakha suffixes belong to the Lamunkhin Even morpheme repertoire.

(12) a. Lamunkhin Even bi: emie ia-dzi-m iečemeče-j-ebin

(beseda_0977_RDA) 1SG also.Y HESIT-FUT-1SG to.race-CONN-PRS.1SG.Y

'I will also take part in the (reindeer) race.'

b. Lamunkhin Even

tara-w hir-gara-ri-w ńajuku-kọ:n

DIST-ACC to.milk-HAB-PST-POSs.1sG quietly-DIM[EMPH]

ńajuku-kọ:n hir-nikan ulam ulam

quietly-DIM[EMPH] to.milk-SIM.CVB gradually.Y gradually.Y

ia-ri-w tat-ti-w

HESIT-PST-1SG learn-PST-1SG

'That (reindeer doe) I milked quietly, quietly milking I gradually learned.'

c. Lamunkhin Even

dzebeme-d-di narọta-1 ia-galda mut

be.hungry-PROG-IPFV.PTCP people.R-PL HESIT-IMP.1PL 1PL

il-galda

stand.up-IMP.1PL

'Hungry people, let's stand up.'

The following humorous verse recorded from an Old Russian Settler community in Yakutia (13) provides further support for the ability of fully bilingual speakers to directly insert inflectional morphemes from one of their languages into the other (Sakha elements underlined).

(13) Old Russian Settlers, Yakutia

(Golovko 2003:188; transcription and translation adjusted, glosses mine)

simpatičnij devuška-nii

pretty.M girl.F-ACC.Y

olus olus ja ljublju

very.Y very.Y 1sG love.PRS.1sG

iz-za ètogo, naverno,

because.of that.GEN probably

tü:n-ü bï:ha ja ne splju

night-ACC.Y throughout.Y 1SG NEG sleep.PRS.1sG

'A pretty girl very very much I like, probably because of that I don't sleep all night'

Here, the Sakha accusative case marker is added to the Russian noun devuška 'girl' to achieve both the necessary meter as well as a rhyme with the following line; Russian is presumably the matrix language of the whole verse. Such an insertion of a structural case marker for artistic purposes again shows that fully bilingual speakers are able to 
freely draw from both of their linguistic repertoires, and that direct affix copying of inflectional morphology is possible. ${ }^{12}$

6. Discussion AND CONCLUSIONS. The data thus demonstrate that Lamunkhin Even speakers who are fully bilingual in Sakha are able to insert Sakha inflectional suffixes directly into their Even matrix language. This is probably facilitated by several structural factors, namely (i) the typological congruity of the languages, (ii) the easy recognition of Sakha verb stems and thus easy segmentability, and (iii) the specifics of the Sakha TAM system.

First of all, both lects are agglutinative (Sakha even more so than Lamunkhin Even), with rich suffixing morphology. This makes it easy to segment words and to identify individual suffixes. That bilingual individuals are indeed able to identify separate morphemes is shown by comments made during a task in which speakers were asked to judge the acceptability of sentences containing complex copies. In several cases, participants in the task pointed out that the endings in certain verbs were Sakha (e.g. 14a,b).

(14) a. Lamunkhin Even

anja-j-dak-pit $=$ di:

(judgment task) spend.the.night-CONN-ASS-1PL=EMPH.Y

'we spent the night, right' $\rightarrow$ 'Sakha ending' (M29)

b. Lamunkhin Even

(judgment task)

oda-jakta:k-kit

finish-NEC-2PL.Y

'you have to finish' $\rightarrow$ 'the ending is Sakha' (M57)

In this context, the probable indirect process of copying the negative assertive can be explained by typological incongruence: like other Tungusic languages (cf. Hölzl 2015), Even expresses negation with the help of a negative auxiliary that carries tense and subject agreement marking, while the lexical verb carries aspectual marking and is in an invariant negative converbal form (see $3 \mathrm{~b}$ or 11 above). Sakha, in contrast, expresses negation with the help of various negative suffixes that attach to the lexical verb stem.

Second, since in Sakha (but not in Even) the bare verb stem functions as a $2 \mathrm{sg}$ imperative, bare verb stems occur in normal spoken speech. This facilitates the recognition of the verb stem in morphologically complex forms and correspondingly permits easier identification of the suffixes (15a,b) and subsequent transfer to Even roots (15c).

(15) a. Sakha

če üčügej-dik olor die-te, ...

PTL good-ADVR live[IMP.2SG] say-PST.3SG

“"Well, live well” he said ...'

b. Sakha

(RaxA_283)

ol kurduk olor-do $\chi$-put di: oyo-lor-bun kïtta

that like live-Ass-1PL EMPH child-PL-ACC.1sG with

'So that's how we live, with my children.'

c. Lamunkhin Even

herile-du a:yna-j-dak-pït $=$ di:

(MKK_bear_047 [ex. 6b in Pakendorf 2009]) stony.mountain-DAT stop.for.the.night-CONN-ASS.Y-1PL.Y=EMPH.Y

'... we spent the night on a stony mountain, right.'

\footnotetext{
${ }^{12}$ As pointed out by an anonymous referee, this humorous poem illustrates the conscious and creative manipulation of language by bilinguals, raising the question of whether deliberate manipulations may have been involved in the copying of the Sakha paradigms into Lamunkhin Even. The Lamunkhin corpus data do not
} 
Lastly, Sakha has hardly any dedicated TAM markers; rather, the combination of a multifunctional suffix ${ }^{13}$ (generally a participle) with a specific set of subject agreement suffixes results in a particular TAM reading. It is thus not possible to simply copy the assertive suffix, for example; in order to obtain the desired reading, the mood suffix has to be combined with the correct set of subject agreement suffixes. This helps to explain why speakers of Lamunkhin Even copied both the TAM and the person-marking suffixes from Sakha (Pakendorf 2014:301-5).

In conclusion, the data from Lamunkhin Even discussed here demonstrate that direct copying of verbal inflectional affixes is possible, albeit rare. Whether this process was involved in the genesis of Copper Island Aleut can no longer be elucidated. However, it is highly likely that the transfer of the Sakha assertive paradigm into Učur Evenki took place via direct affix copying as well, given that the same enhancing factors as those discussed for Lamunkhin Even would have held in the Učur Evenki-Sakha contact situation. Here, too, the Sakha verb roots would have been easily recognizable and the particular TAM reading of the assertive paradigm would have been achieved only through additional copying of the requisite subject agreement paradigm. Furthermore, Učur Evenki shows the same level of typological similarity with Sakha as Lamunkhin Even. Such typological similarity facilitates the insertion of inflectional morphemes from the model language into the corresponding verb slots in the recipient language. Further research into language contact involving typologically congruent languages might uncover more such cases.

APPENDIX: TABLES OF MORPHEMES ATTESTED IN THE LAMUNKHIN EVEN NARRATIVE CORPUS (from Pakendorf 2015:173, 175)

\begin{tabular}{|c|c|c|}
\hline \multicolumn{3}{|c|}{ LAMUNKHIN EVEN } \\
\hline$-\mathrm{jAk}$ & A:kpIn & -IA $\chi \mathrm{tA}: \chi$-BIn \\
\hline$-\mathrm{jAk}$ & A:kkIn & -IA $\chi \mathrm{tA}: \chi$-GIn \\
\hline$-\mathrm{jAk}$ & A:k & -IA $\chi \mathrm{tA}: \chi$ \\
\hline$-\mathrm{jAk}$ & A:kpIt & -IA $\chi$ tA: $\chi$-BIt \\
\hline$-\mathrm{jAk}$ & A:kkIt // -jAktA:kkI-hnAn & -IA $\chi \mathrm{tA}: \chi$-GIt \\
\hline$-\mathrm{jAk}$ & A:k-A-1 & -IA $\chi \mathrm{tA}: \chi-\mathrm{LAr}$ \\
\hline \multicolumn{3}{|c|}{ TABLE A1. Necessitive mood. } \\
\hline & LAMUNKHIN EVEN & SAKHA \\
\hline $1 \mathrm{SG}$ & -dAgIm & $-\mathrm{Ta} \chi-(\mathrm{I}) \mathrm{m}$ \\
\hline $2 \mathrm{SG}$ & -dAgIn & $-\mathrm{Ta} \chi-(\mathrm{I}) \eta$ \\
\hline $3 \mathrm{SG}$ & $-\mathrm{dAgA}$ & $-\mathrm{Ta} \chi-(\mathrm{t}) \mathrm{A}$ \\
\hline $1 \mathrm{PL}$ & -dAkpIt & -Ta $\chi$-BIt \\
\hline 2PL & & -Ta $\chi$-GIt \\
\hline $3 \mathrm{PL}$ & -dAktArA & -Ta $\chi$-LArA \\
\hline \multicolumn{3}{|c|}{ TABLE A2. Assertive mood. } \\
\hline & LAMUNKHIN EVEN & SAKHA \\
\hline $1 \mathrm{SG}$ & -AbIn & -A -BIn \\
\hline $2 \mathrm{sG}$ & -AgIn & -A -GIn \\
\hline $3 \mathrm{sG}$ & $-\mathrm{Ar}$ & $-\mathrm{Ar}$ \\
\hline $1 \mathrm{PL}$ & -AbIt & -A -BIt \\
\hline $2 \mathrm{PL}$ & & -A -GIt \\
\hline $3 \mathrm{PL}$ & $-\mathrm{AllAr}$ & -Ar -LAr \\
\hline
\end{tabular}

\footnotetext{
provide any indications of wordplay involving the Sakha morphemes, making deliberate change unlikelyalthough this cannot be excluded based on the extant data.

${ }^{13}$ It should be noted that these suffixes are bound morphemes that show no resemblance to auxiliaries, in contrast to Seifart's (2017:409) description.
} 


\begin{tabular}{lll} 
& LAMUNKHIN EVEN & \multicolumn{1}{c}{ SAKHA } \\
1SG & -jAkpIn & -IA $\chi$-BIn \\
2SG & -jAkkIn & -IA $\chi$-GIn \\
3SG & -jA:gIn // -jAn & -IA $\chi-(\mathrm{t})$ In $/ /-$ IAn \\
1PL & & -IA $\chi$-BitIn \\
2PL & & -IA $\chi$-GitIn \\
3PL & -jAktArIn & -IA $\chi$-LArIn \\
IMPERSONAL & - jAkkA & -IA $\chi-$ GA
\end{tabular}

TABLE A4. Hypothetical mood.

\section{REFERENCES}

Adamou, Evangelia. 2012. Verb morphologies in contact: Evidence from the Balkan area. Morphologies in contact, ed. by Martine Vanhove, Thomas Stolz, Aina Urdze, and Hitomi Otsuka, 143-62. Berlin: Akademie.

COMRIE, BERNARD. 2008. Inflectional morphology and language contact, with special reference to mixed languages. Language contact and contact languages (Hamburg studies on multilingualism 7), ed. by Peter Siemund and Noemi Kintana, 15-32. Amsterdam: John Benjamins.

Evans, Nicholas. 2016. As intimate as it gets? Paradigm borrowing in Marrku and its implications for the emergence of mixed languages. Loss and renewal: Australian languages since colonisation (Language contact and bilingualism 13), ed. by Felicity Meakins and Carmel O'Shannessy, 29-56. Berlin: De Gruyter Mouton.

Gardani, Francesco. 2008. Borrowing of inflectional morphemes in language contact. Frankfurt am Main: Peter Lang.

Gardani, Francesco. 2012. Plural across inflection and derivation, fusion and agglutination. Copies versus cognates in bound morphology, ed. by Lars Johanson and Martine Robbeets, 71-97. Leiden: Brill. DOI: 10.1163/9789004230477 005.

Gardani, Francesco; Peter Arkadiev; and Nino AmiridZe. 2015a. Borrowed morphology: An overview. In Gardani et al. 2015b, 1-23.

Gardani, Francesco; Peter Arkadiev; and Nino Amiridze (eds.) 2015b. Borrowed morphology. (Language contact and bilingualism 8.) Berlin: De Gruyter Mouton.

Golovko, EvgeniY V. 1996. A case of nongenetic development in the Arctic area: The contribution of Aleut and Russian to the formation of Copper Island Aleut. Language contact in the Arctic: Northern pidgins and contact languages (Trends in linguistics: Studies and monographs 88), ed. by Ernst Håkon Jahr and Ingvild Broch, 63-77. Berlin: Mouton de Gruyter.

Golovko, EvgEnIY V. 2003. Language contact and group identity: The role of 'folk' linguistic engineering. The mixed language debate: Theoretical and empirical advances (Trends in linguistics: Studies and monographs 145), ed. by Yaron Matras and Peter Bakker, 177-207. Berlin: Mouton de Gruyter.

Grant, ANTHONY. 2008. Contact-induced change and the openness of 'closed' morphological systems: Some cases from native America. Journal of Language Contact 2(1).165-86. DOI: 10.1163/000000008792525264.

Grant, Anthony. 2012. Bound morphology in English (and beyond): Copy or cognate? Copies versus cognates in bound morphology, ed. by Lars Johanson and Martine Robbeets, 99-122. Leiden: Brill. DOI: 10.1163/9789004230477_006.

HölzL, ANDREAS. 2015. A typology of negation in Tungusic. Studies in Language 39.11859. DOI: $10.1075 / \mathrm{sl} .39 .1 .05$ hoe.

Jake, Janice L., and Carol Myers-Scotton. 2009. Which language? Participation potentials across lexical categories in codeswitching. Multidisciplinary approaches to code switching, ed. by Ludmila Isurin, Donald Winford, and Kees de Bot, 207-42. Amsterdam: John Benjamins.

Johanson, LaRs. 1992. Strukturelle Faktoren in türkischen Sprachkontakten. (Sitzungsberichte der Wissenschaftlichen Gesellschaft an der Johann-Wolfgang-Goethe-Universität Frankfurt am Main 29:5.) Stuttgart: Steiner.

Kossmann, MaArten. 2010. Parallel system borrowing: Parallel morphological systems due to the borrowing of paradigms. Diachronica 27.459-87. DOI: 10.1075/dia.27.3 $.03 \mathrm{kos}$. 
Matras, YARON. 2007. The borrowability of structural categories. Grammatical borrowing in cross-linguistic perspective, ed. by Yaron Matras and Jeanette Sakel, 31-73. Berlin: Mouton de Gruyter.

Matras, Yaron. 2009. Language contact. Cambridge: Cambridge University Press.

MATRAS, YARON. 2015. Why is the borrowing of inflectional morphology dispreferred? In Gardani et al. 2015b, 47-80.

Meakins, Felicity. 2011. Borrowing contextual inflection: Evidence from northern Australia. Morphology 21.57-87. DOI: 10.1007/s11525-010-9163-4.

MenOvŠČIKov, GeORGIJ A. 1968. Aleutskij jazyk [Aleut]. Jazyki narodov SSSR, Tom pjatyj: Mongol'skie, tunguso-man'čžurskie i paleoaziatskie jazyki [The languages of the USSR, vol. 5: Mongolian, Tungusic, and Paleosiberian languages], ed. by Petr Jakovlevič Skorik, Valentin Aleksandrovič Avrorin, Trofim Alekseevič Bertagaev, Georgij Alekseevič Menovščikov, Orest Petrovič Sunik, and Ol'ga Aleksandrovna Konstantinova, 386-406. Leningrad: Nauka.

Mithun, Marianne. 2012. Morphologies in contact: Form, meaning, and use in the grammar of reference. Morphologies in contact, ed. by Martine Vanhove, Thomas Stolz, Aina Urdze, and Hitomi Otsuka, 15-36. Berlin: Akademie.

Myers-Scotton, Carol. 2002. Contact linguistics: Bilingual encounters and grammatical outcomes. Oxford: Oxford University Press.

Myers-Scotton, Carol. 2008. Language contact: Why outsider system morphemes resist transfer. Journal of Language Contact 2(1).21-41. DOI: 10.1163/000000008792525 318.

Myreeva, Anna N. 1964. Očerk govora učurskix èvenkov [A sketch of the dialect of the Učur Evenks]. Očerki Učurskogo, majskogo i tottinskogo govorov, ed. by Agniya V. Romanova and Anna N. Myreeva, 6-74. Moscow: Izdatel'stvo Nauka.

Novikova, KlavdiJa A. 1980. Očerki dialektov èvenskogo jazyka: Glagol, služebnye slova, teksty, glossarij [Sketches of Even dialects: Verb, auxiliary words, texts, glossary]. Leningrad: Nauka.

PAKendorf, BrigitTe. 2007. Contact in the prehistory of the Sakha (Yakuts): Linguistic and genetic perspectives. (LOT dissertation series 170.) Utrecht: LOT.

PAKendorf, BrigitTe. 2009. Intensive contact and the copying of paradigms: An Even dialect in contact with Sakha (Yakut). Journal of Language Contact 2(2).85-110. DOI: 10.1163/000000009792497724.

Pakendorf, BrigitTe. 2014. Paradigm copying in Tungusic: The Lamunkhin dialect of Ėven and beyond. Paradigm change in historical reconstruction: The Transeurasian languages and beyond, ed. by Martine Robbeets and Walter Bisang, 287-310. Amsterdam: John Benjamins.

PAKendoRf, BrigitTe. 2015. A comparison of copied morphemes in Sakha (Yakut) and Ėven. In Gardani et al. 2015b, 157-87.

SeIfart, Frank. 2012. The principle of morphosyntactic subsystem integrity in language contact: Evidence from morphological borrowing in Resígaro (Arawakan). Diachronica 29.471-504. DOI: 10.1075/dia.29.4.03sei.

Seifart, Frank. 2015. Direct and indirect affix borrowing. Language 91.511-32. DOI: 10.1353/lan.2015.0044.

SEIFART, FranK. 2017. Patterns of affix borrowing in a sample of 100 languages. Journal of Historical Linguistics 7.389-431. DOI: 10.1075/jhl.16002.sei.

Thomason, Sarah Grey. 1997. Mednyj Aleut. Contact languages: A wider perspective (Creole language library), ed. by Sarah Grey Thomason, 449-68. Amsterdam: John Benjamins.

Thomason, Sarah Grey. 2015. When is the diffusion of inflectional morphology not dispreferred? In Gardani et al. 2015b, 27-46.

WeinReich, Uriel. 1953. Languages in contact: Findings and problems. New York: Linguistic Circle of New York. 